\title{
Discussion: The design of temporary excavation support to Eurocode 7
}

\author{
P. D. Markham \\ RNP Associates, Sutton Coldfield, UK \\ H. Roscoe MSC, DIC, MICE \\ Retired
}

\section{Contribution by H. Roscoe}

The author is to be congratulated (Markham, 2012) for highlighting many of the difficulties that practitioners face in designing routine retaining walls to BS EN 1997-1:2004 (Eurocode 7) (BSI, 2004a). The points about accidental overdig and the limitations of a statistical approach when applied to heterogeneous fill material are well made.

Thermal effects are unlikely to have any significant effect on temporary steel props supporting comparatively low flexibility walls. Provided that the structural checks described by Twine and Roscoe (1999) are satisfied, it is not necessary to increase the prop load to allow for temperature effects.

It may be that Eurocode 7 gives the designer less choice in the way that partial factors are to be applied than Section 4 of the paper implies. UK engineers following Design Approach 1, Combinations 1 and 2, are told (Clause 2.4.7.3.4.2) that partial factors are applied to actions and to ground strength parameters (only?).

Most would accept CIRIA C580 (Gaba et al., 2003) as a guide to previous good practice. The author's conclusion that designs to Eurocode 7 give lower margins of safety than are recommended in CIRIA C580 is indeed surprising, and as he states is contrary to Eurocode 7 requirements. This may follow from the way that the so-called 'single source principle' is applied in the paper. Eurocode 7 (Clause 2.4.2) states that this principle may apply 'in some situations'. Neither Eurocode 7 nor the UK National Annex (BSI, 2004b) describes these situations, but it is doubtful that designers may invoke it wherever they choose. Engineers should aim to apply the partial factors given in the National Annex in the way envisaged when they were set down. Unfortunately the National Annex does not tell us what this is.

Where the single source principle applies, a single partial factor is to be applied to the sum of the unfavourable and favourable actions. For retaining wall design this would seem to imply a return to the use of net total pressure diagrams that are fraught with difficulties.

Bond and Harris (2008) explain that the single source principle requires the designer to make two sets of calculations, applying the partial factors for favourable and for unfavourable actions successively, and selecting the less favourable result. This does not seem to provide the reduction in design effort that is claimed.

Bond and Harris (2008) make extensive use of the single source principle in both their text and the examples that deal with retaining wall design. A key feature of their book is to present Eurocode 7 'warts and all', and their approach to this topic may be intended to stimulate debate rather than to provide 'design guidance'. It is strange that in a system that verifies designs by increasing unfavourable actions and decreasing favourable actions we should be applying the same factor to both. Surely it would be clearer to separate unfavourable and favourable actions, and to factor them as appropriate? If this were done, the reported discrepancy between Eurocode 7 calculations and those based on CIRIA C580 might be less significant than currently appears.

\section{Contribution by A. Beal}

The author is to be congratulated on a thoughtful and thoughtprovoking paper (Markham, 2012). It could be argued that it is rather late in appearing, as several years have passed since Eurocode 7 was published (BSI, 2004a), and BS 8004 (BSI, 1986) and BS 8002 (BSI, 1994) were withdrawn by BSI in March 2010. Therefore, if the Eurocode changeover was proceeding as planned, all geotechnical design in the UK since 2010 should have been carried out in accordance with Eurocode 7. However, in practice the take-up of Eurocodes has been slow, and experience of them in use is still limited. In this situation the variety of interpretations of Eurocode 7 recommendations and possible differences the author has found from existing practice are disturbing.

The objective of engineering design has always been to produce the most economical structure that is also safe and serviceable. Where Eurocode 7 and existing practice give different results, either one must be overconservative, or else the other must be potentially unserviceable or unsafe. In the cases where differences have been identified, what was the judgement? Were the Eurocode 7 designs considered to be 'economical, safe and serviceable' and existing practice 'unsafe' or 'overconservative', or was it the other way round? It is now four years since Eurocode 7 was first cleared for use in the UK; it would be worrying if we still did not know the answers. 
Design to Eurocode 7 is not actually mandatory for publicly funded work. In the Public Contracts Regulations 2006 (HMG, 2006), Clause 9(10) states that an authority that specifies technical requirements in terms of Eurocodes

shall not reject an offer on the basis that the materials, goods or services offered do not comply with those technical specifications if an economic operator proves... by any appropriate means that the... solutions... satisfy the requirements of those technical specifications in an equivalent manner.

Therefore designs prepared using other guidance should still be acceptable, as long as the results are similar to Eurocode 7 or more conservative.

The reported difficulties in applying Eurocode 7 partial factors are not altogether surprising: early partial factor structural codes encountered problems when applied to more complex structures than simply supported beams. Codes such as CP110 (BSI, 1972) applied maximum and minimum factored dead load span by span for worst effect, which caused havoc in continuous beams and balanced structures (Beal, 1979). Later codes, such as BS 5400:1978 (BSI, 1978) and BS 8110:1985 (BSI, 1985), solved this by factoring dead load (DL) uniformly (like the Eurocode 7 'single source' approach), but then overturning calculations became a problem. Table A1.2(A) in BS EN 1990:2002 (BSI, 2002) tries to reconcile the two requirements by applying uniform (1.0DL) and span-by-span (1.35DL/1.15DL) loadings, but this solution brings a price in complexity: for a four-span beam there may be six different patterns of factored dead load to consider.

There are also problems in slender column buckling, where strength depends on stiffness, rather than on material strength (Beal, 1986), and in post-tensioned prestressed concrete, where resistance relies on an 'action', and $\gamma_{\mathrm{m}}$ may not be mobilised at failure. Forty years after the codes appeared, these are still unsolved problems. It may take some time to reconcile partial factors with the complexities of geotechnical design.

It is worth remembering that in Eurocodes the loads, material strengths and partial factors are not actually based on rigorous theory; they still have arbitrary values set to give similar results to previous codes (Beal, 2011). Where Eurocode 7 produces results that conflict with existing practice, we cannot assume that the Eurocode 7 results are necessarily the most appropriate.

\section{Author's reply}

Eurocode 7 is not easy to use, and many clauses are open to interpretation. I wanted to start some debate, with a view to clarifying some of the uncertainty, so the comments from both contributors are most welcome.

In response to H. Roscoe, the note to Clause 2.4.7.3.4.2 is one such case where the meaning is ambiguous. The clause states that
'In Combinations 1 and 2, partial factors are applied to actions and to ground strength parameters.' However, depending on the calculation, it is also necessary to apply partial factors elsewhere in the calculation - for example, to resistances $\left(\gamma_{R}\right)$ or to the effect of actions $\left(\gamma_{\mathrm{E}}\right)$, so, like many other clauses, this clause should not be read in isolation.

In a limit equilibrium analysis of a retaining wall, it is not clear where the earth pressure, near the toe of the wall, changes from being an unfavourable action to a favourable action. Different partial factors would apply to each, as described in Section 2 of the paper. The method of applying a factor of 1.35 to the soil on the retained side of the wall and a factor of 1.0 to the soil on the excavated side of the wall is incorrect near the toe of the wall, where the soil on the retained side becomes favourable. It is not clear how it was envisaged that these partial factors would be applied but applying $\gamma_{\mathrm{F}}=1.35$ to the retained soil applies the factor of 1.35 to a favourable action, which is contrary to several clauses of Eurocode 7, such as 9.5.1(3)P, which states

Calculations of the magnitudes of earth pressures and directions of forces resulting from them shall take account of ... the amount and direction of the movement of the wall relative to the ground.

It would appear to be difficult to follow this principle using current limit equilibrium methods; the so-called 'single source principle', where the same partial factor is applied to favourable and unfavourable actions, is a way around this difficulty.

In response to A. Beal: as stated in Section 3 of the paper, several comparisons of calculated and observed prop forces have shown that the high factors of safety recommended in CIRIA Report C580 (Gaba et al., 2003) are necessary for a safe design. Hence it follows that the use of a lower factor of safety, which calculations to Eurocode 7 can produce, could result in a potentially unsafe design. Therefore it is necessary to perform calculations in accordance with Eurocode 7, and then use the results with caution.

It has also been pointed out that the formulae in Section 3.1 of the paper are incorrect.

The correct equations are

$$
\sigma_{\mathrm{a}}=K_{\mathrm{a}} \sigma_{\mathrm{va}}-K_{\mathrm{ac}} c_{\mathrm{u}}
$$

$$
\sigma_{\mathrm{p}}=K_{\mathrm{p}} \sigma_{\mathrm{vp}}+K_{\mathrm{pc}} c_{\mathrm{u}}
$$

Note that there is no prime $\left(^{\prime}\right)$ on $\sigma_{\mathrm{va}}$ or $\sigma_{\mathrm{vp}}$; they are total stresses, not effective stresses. The correct equations were used in the subsequent calculations. My apologies for the error. 


\section{REFERENCES}

Beal AN (1979) What's wrong with load factor design? Proceedings of the Institution of Civil Engineers, Part 1 66: 595-604.

Beal AN (1986) The design of slender columns. Proceedings of the Institution of Civil Engineers, Part 2 81: 397-414.

Beal AN (2011) A history of the safety factors. The Structural Engineer 89(20): 20-26.

Bond A and Harris A (2008) Decoding Eurocode 7. Taylor and Francis, Abingdon, UK.

BSI (1972) CP 110-1:1972. The structural use of concrete. Part 1: Design, materials and workmanship. BSI, London, UK.

BSI (1978) BS 5400:1978. Steel, concrete and composite bridges. Part 2: Specification for loads. BSI, London, UK.

BSI (1985) BS 8110-1:1985. Structural use of concrete: Code of practice for design and construction. BSI, London, UK.

BSI (1986) BS 8004:1986. Code of practice for foundations. BSI, London, UK.

BSI (1994) BS 8002:1994. Code of practice for earth retaining structures. BSI, London, UK.
BSI (2002) BS EN 1990:2002. Eurocode: Basis of structural design. BSI, London, UK.

BSI (2004a) BS EN 1997-1:2004. Eurocode 7: Geotechnical design. Part 1: General rules. BSI, London. UK.

BSI (2004b) NA to BS EN 1997. UK National Annex to Eurocode 7 : Geotechnical design - Part 1: General rules. BSI, London, UK.

Gaba AR, Simpson B, Powrie W and Beadman DR (2003) CIRIA Report C580: Embedded Retaining Walls: Guidance for Economic Design. Construction Industry Research and Information Association, London, UK.

HMG (Her Majesty's Government) (2006) Public Contract Regulations 2006. The Stationery Office, London, UK, Statutory Instrument 2006 No. 5.

Markham PD (2012) The design of temporary excavation support to Eurocode 7. Proceedings of the Institution of Civil Engineers - Geotechnical Engineering 165(1): 3-12.

Twine D and Roscoe H (1999) CIRIA Report C517: Temporary Propping of Deep Excavations: Guidance on Design. Construction Industry Research and Information Association, London, UK. 